\title{
TP53 Polymorphisms in Sporadic North Indian Breast Cancer Patients
}

\author{
Sarika Sharma ${ }^{1}$, Vasudha Sambyal $^{1}$, Kamlesh Guleria ${ }^{1 *}$, Mridu Manjari $^{2}$, Meena \\ Sudan $^{3}$, Manjit Singh Uppal ${ }^{4}$, Neeti Rajan Singh ${ }^{4}$, Darpan Bansal ${ }^{4}$, Arun Gupta $^{4}$
}

\begin{abstract}
Background: The purpose of this study was to evaluate the potential association of five (p.P47S, p.R72P,PIN3 Ins16bp, p.R213R and r.13494g>a) polymorphisms of TP53 with the risk of developing breast cancer in North Indian Punjabi population. Methods: We screened DNA samples of 200 sporadic breast cancer patients (197 females and 3 males) and 200 unrelated healthy, gender and age matched individuals for the polymorphisms. Results: For the p.P47S polymorphism, we observed the PPgenotype in 99.5\% of the patients and PS genotype in only 1 patient. All the controls had the wild type PP genotype. The frequency of RR, RP and PP genotype of p.R72P was $23.5 \%$ vs $33.5 \%, 51.5 \%$ vs $45.5 \%$ and $25 \%$ vs $21 \%$ in patients and controls respectively. Heterozygous (RP) genotype was increased in breast cancer patients as compared to controls (51.5 vs $45.5 \%)$ and showed 1.61 fold significantly increased risk for breast cancer $(\mathrm{OR}=1.61,95 \% \mathrm{CI}, \mathbf{1 . 0 1 - 2 . 5 8}, \mathrm{p}=\mathbf{0 . 0 4})$. In breast cancer patients the frequencies of A1A1, A1A2 and A2A2 genotypes of PIN3 Ins16bp polymorphism were 67\%, $26 \%$ and $7 \%$ respectively whereas in controls the genotype frequencies were $68.5 \%, 27.5 \%$ and $4 \%$ respectively, with no significant difference. For p.R213R (c.639A >G), all individuals had homozygous wild type genotype. The frequencies of GG, GA and AA genotypes of TP53 r.13494g>a polymorphism were 62 vs $67.5 \%, 33 \mathrm{vs} 28 \%$ and 5 vs $4.5 \%$ in patients and controls respectively, again without significant difference. We observed that RPA1A1 genotype combination of p.R72P and PIN3 Ins16bp and RP-GG combination of p.R72P and r.13494g>a polymorphism showed significant risk of breast cancer $(\mathrm{OR}=1.65,95 \% \mathrm{CI}$ : $0.98-2.78, \mathrm{p}=0.05$; $\mathrm{OR}=1.72,95 \% \mathrm{CI}$ : 1.01-2.92, $\mathrm{p}=0.04)$. Conclusion: The results of present study indicated that among the five TP53 polymorphisms investigated, the p.R72P polymorphism, and the RP-A1A1 and RP-GG genotype combination contribute to breast cancer susceptibility in North Indians.
\end{abstract}

Keywords: Breast cancer - TP53 polymorphisms - susceptibility - North Indians

Asian Pac J Cancer Prev, 15 (16), 6871-6879

\section{Introduction}

Common genetic polymorphisms with possible effects on function and/or protein expression within genes involved in essential cellular pathways like carcinogen metabolism, DNA repair, cell cycle control and cell proliferation could predispose individuals to cancer (Medeiros et al., 2004; Pinto et al., 2004; Costa et al., 2005; Costa et al., 2007). Accumulation of various genetic alterations, including amplification of oncogenes and mutation or loss of tumor suppressor genes is reported to be among the causes of breast cancer (Wajapeye and Somasundaram, 2004). Breast cancer is one of the most common malignancies in women, causing over 4,00,000 deaths yearly worldwide (Walerych et al., 2012). Involvement of several breast cancer predisposition genes like TP53, FGFR, MYC, BRCA1 and BRCA2 in various cancers indicates that different cancer type may show common predisposition mechanisms which include commonly inherited SNPs.

Tumor suppressor gene TP53 (OMIM 191170) is a multifunctional tetrameric transcription factor involved in the control of cell cycle progression, DNA repair, apoptosis and senescence (Levine and Oren, 2009). Human p53 is a nuclear phosphoprotein of molecular weight $53 \mathrm{kDa}$, encoded by a $20 \mathrm{~kb}$ gene located on $17 \mathrm{p} 13.1$ comprising 11 exons and 10 introns (Lamb and Crawford, 1986; Isobe et al., 1986). TP53 is often mutated in a variety of human cancers and is also highly polymorphic with more than 200 single nucleotide polymorphisms (SNPs) been identified in both coding and non-coding regions (http://www-p53. iarc.fr/). A large number of studies have documented the association of common TP53 polymorphisms with cancer risk (Whibley et al., 2009).

${ }^{1}$ Human Cytogenetics Laboratory, Department of Human Genetics, Guru Nanak Dev University, ${ }^{2}$ Department of Pathology, ${ }^{3}$ Department of Radiotherapy, ${ }^{4}$ Department of Surgery, Sri Guru Ram Das Institute of Medical Sciences and Research, Amritsar, Punjab, India*For correspondence: guleria_k@yahoo.com 
The p.R72P(rs 1042522) the non-synonymous single nucleotide polymorphism is one of the most extensively studied polymorphisms of TP53 located in a prolinerich domain of the protein, which has been known to be important for the growth suppression and apoptotic functions (Soussi and Lozano, 2005). This polymorphism exists in two isoforms (Arg72 and Pro72) which differ in their biochemical and biological properties (Thomas et al., 1999). The TP53 Arg72 form induces apoptosis more efficiently than the Pro72 form (Dumont et al., 2003; Pim and Banks, 2004). However, the Pro 72 variant is more efficient at inducing cell cycle arrest in the G1 phase, allowing better repair of damaged DNA (Oersted et al., 2007). Various meta-analyses studies reported the involvement of p.R72P in susceptibility to various cancer types including gastric (Zhou et al., 2007), lung (Dai et al., 2009) and breast (Zhang et al., 2010). However, studies on association of breast cancer risk with p.R72P polymorphism have not yielded consistent results.

Codon 47 (p.P47S (rs1800371)), is the second functionally significant polymorphism located in the $\mathrm{N}$-terminal transactivation domain of p53 which leads to a non-synonymous amino acid substitution of proline with serine. It has been documented that Ser47 variant has upto 5-fold decreased ability to induce apoptosis compared with wild type Pro47 variant (Li et al., 2005). However, only small numbers of studies have been performed on p.P47S and its association with cancer due to the low frequency of this polymorphism (Murphy, 2006).

Another rare polymorphism pR213R (rs1800372) at codon 213 results from silent alteration of CGA to CGG within the coding region of the p53 gene. The rare polymorphic allele was observed in $3.2 \%$ of lung and breast cancer patients (Carbone et al., 1991). But in a study on healthy Turkish population and Turks with different types of tumours no association between this polymorphism and the development of tumours was observed (Iihan et al., 1995).

Intronic polymorphisms may influence codingregion sequence alterations that increase the likelihood of a deleterious phenotype (Malkinson and You, 1994). PIN3 Ins 16bp duplication (rs 17878362) in intron 3 and $13494 \mathrm{~g}$ to a transversion (rs 1625895) in intron 6 have been suggested to affect the function and expression of p53 (McDaniel et al., 1991; Chumakov and Jenkins, 1991; Lazar et al., 1993; Hillebrandt et al., 1997). PIN3 Ins 16bp polymorphism has been associated with a reduced level of p53 mRNA and decreased apoptotic indices and DNA repair capacity in lymphoblastoid cell lines (Wu et al., 2002; Gemignani et al., 2004). Several case control studies have correlated the intron 3 duplication with an increased risk of various cancers, with the most consistent association reported for breast (Wang-Gohrke et al., 2002; Costa et al., 2008) and colorectal cancers (Gemignani et al., 2004; Perfumo et al., 2006). In a recent meta-analysis, association of A2A2 genotype of PIN3 Ins16bp polymorphism with increased cancer risk has been documented in Indian, Mediterranean and Northern European populations (Sagne et al., 2013).

Another intronic polymorphism r.13494g $>$ a is localised in intron 6 of TP53, which is one of the hot spots region for TP53 muation. The r.13494g>a sequence variant was observed in six affected members of a Li-Fraumeni family, and in only one out of 184 healthy controls (Avigad et al., 1997). Significant association of this polymorphism with the risk of developing breast and colon cancers has been observed (Peller et al., 1995). These nucleotide changes may act via novel mechanisms of gene regulation that appears to be important for tumor formation (Surekha et al., 2011). On the contrary in another study, no difference in the distribution of $\mathrm{r} .13494 \mathrm{~g}>\mathrm{a}$ polymorphism was observed in the breast cancer patients and controls (Mavridou et al., 1998).

In Punjab an agragarian state in North India, increased cancer incidence possibly due to increased use of agricultural chemicals has been reported (The Tribune, 2013). According to a report from Department of Health and Family Welfare India, the cancer prevalence per million in the different regions of Punjab is: Malwa region 1089, Majha region 647 and Doaba region 881 (DHFW, 2013). Breast cancer is the most prevalent cancer among females in Punjab.

TP53 is a major tumor suppressor gene playing role in carcinogenesis and response to therapy. Among the TP53 polymorphisms there are more reported studies on the p.R72P, PIN3 Ins 16bp in breast cancer but very few data is available for p.P47S, p.R213R and 13494g >a polymorphisms. So the present study was aimed to study the potential association of five (p.P47S, p.R72P, PIN3 Ins16bp, p.R213R and r.13494g $>$ a) polymorphisms of TP53 with the risk of developing breast cancer in North Indian Punjabi population. The combined effects of these five polymorphisms on cancer risk could be more significant than the individual effect of any one of them alone.

\section{Materials and Methods}

\section{Study subjects}

This study was approved by the ethical committee constituted by Guru Nanak Dev University, Amritsar, Punjab, India. The patients were investigated at Sri Guru Ram Das Institute of Medical Sciences and Research, Vallah, Amritsar, Punjab, India. Clinically confirmed breast cancer patients, who had not undergone blood transfusion and received any therapy were included in the study. Gender and age matched $( \pm 5$ years) unrelated healthy individuals from the same geographical areas as that of patients, having no family history of cancer or other related comorbidities up to three generations were recruited as controls. All the subjects were from Majha region of Punjab. Relevant information including self reported personal history and disease history of each subject was recorded on a pre-tested structured questionnaire by interview or from medical records. After informed consent, $5 \mathrm{ml}$ venous blood was collected from each subject in $0.5 \mathrm{M}$ EDTA.

DNA extraction and genotyping of TP53 polymorphisms

The genomic DNA was extracted from peripheral blood lymphocytes using standard phenol chloroform method (Adeli and Ogbonna, 1990). The quantity and 
TP53 Polymorphisms in Sporadic North Indian Breast Cancer Patients

quality of DNA was checked by gel electrophoresis. Four polymorphisms (p.P47S, p.R72P, p.R213R and r.13494g $>a$ ) of TP53 were screened using PCR-RFLP method. PIN3 Ins 16bp was analysed by direct PCR. The PCR reaction was carried out in a $15 \mu 1$ volume containing $1 \mathrm{X}$ PCR buffer, $0.4 \mu 1 \mathrm{dNTPs}$ mixture, 6 picomole primers (Sigma), 1 U Taq DNA Polymerase (Bangalore GeNei). DNA samples were amplified using specific primer sequences and conditions (Table 1). A negative control without DNA template was included in each reaction. The amplified PCR products were analysed on $2 \%$ ethidium bromide stained agarose gel. PCR products were digested with appropriate restriction enzymes (Table 1) following the manufacturer instructions (New England Biolabs, Beverly, MA). The restriction digestion products were analysed on $2.3 \%$ ethidium bromide stained agarose gel. The genotype of each sample was assigned on the basis of fragments obtained after digestion (Table 1).

The genotyping was performed without the knowledge of the clinical status of the subjects. Ten percent of DNA samples were reanalyzed and results of both sets of analyses were $100 \%$ concordant.

Table 1. Details of TP53 Polymorphisms and Screening Conditions

\begin{tabular}{|c|c|c|c|c|c|c|c|}
\hline $\begin{array}{l}\text { Variant } \\
\text { (RefSNP) }\end{array}$ & $\begin{array}{l}\text { Genotyping } \\
\text { Method }\end{array}$ & $\begin{array}{c}\text { Primers } \\
\text { References }\end{array}$ & $\begin{array}{c}\text { PCR } \\
\text { product size } \\
\text { (bp) }\end{array}$ & $\begin{array}{c}\text { Annealing } \\
\text { Temperature, } \\
\mathrm{MgCl}_{2}\end{array}$ & $\begin{array}{c}\text { Restriction } \\
\text { enzyme }\end{array}$ & $\begin{array}{l}\text { Allele } \\
\text { Size } \\
(\mathrm{bp})\end{array}$ & Expected Fragment \\
\hline \multirow{10}{*}{$\begin{array}{l}\text { p.P47S } \\
\text { (rs1800371) } \\
\text { p.R72P } \\
\text { (rs1800371) } \\
\text { PIN3 Ins 16bp } \\
\text { (rs17878362) } \\
\text { p.R213R } \\
(\text { rs1800372) } \\
\text { r.13494g>a } \\
(\text { rs1625895) }\end{array}$} & \multirow[t]{2}{*}{ PCR-RFLP } & \multirow[t]{2}{*}{ Pinto et al., 2008} & \multirow[t]{2}{*}{$201 / 185^{*}$} & \multirow[t]{2}{*}{$59^{\circ} \mathrm{C}, 1.5 \mathrm{mM}$} & \multirow[t]{2}{*}{ MspI } & $S$ & $201 / 185$ \\
\hline & & & & & & $\mathrm{P}$ & $156 / 140$ and 45 \\
\hline & \multirow[t]{2}{*}{ PCR-RFLP } & \multirow[t]{2}{*}{ Kazemi et al., 2009} & \multirow[t]{2}{*}{279} & \multirow[t]{2}{*}{$59^{\circ} \mathrm{C}, 1.5 \mathrm{mM}$} & \multirow[t]{2}{*}{ BstUI } & $\mathrm{P}$ & 279 \\
\hline & & & & & & $\mathrm{R}$ & 160 and 119 \\
\hline & \multirow[t]{2}{*}{ PCR } & \multirow[t]{2}{*}{ Costa et al., 2008} & \multirow[t]{2}{*}{119 or 135} & \multirow[t]{2}{*}{$61^{\circ} \mathrm{C}, 1.5 \mathrm{mM}$} & \multirow[t]{2}{*}{ - } & A1 & 119 \\
\hline & & & & & & $\mathrm{A} 2$ & 135 \\
\hline & \multirow[t]{2}{*}{ PCR-RFLP } & \multirow[t]{2}{*}{ Pilger et al., 2008} & \multirow[t]{2}{*}{1621} & \multirow[t]{2}{*}{$59^{\circ} \mathrm{C}, 1.0 \mathrm{mM}$} & \multirow[t]{2}{*}{ TaqI } & A & $926,383,312$ \\
\hline & & & & & & G & 926,695 \\
\hline & \multirow[t]{2}{*}{ PCR-RFLP } & \multirow[t]{2}{*}{ Pilger et al., 2008} & \multirow[t]{2}{*}{1621} & \multirow[t]{2}{*}{$59^{\circ} \mathrm{C}, 1.0 \mathrm{mM}$} & \multirow[t]{2}{*}{ MspI } & G & $\begin{array}{l}356,299,277, \\
277,168, \\
124,120\end{array}$ \\
\hline & & & & & & A & $\begin{array}{l}633,299,277 \\
168,124,120\end{array}$ \\
\hline
\end{tabular}

*Size divergence is due to $16 \mathrm{bp}$ ins/del polymorphism in intron 3

Table 2. Genotype and Allele Distribution of TP53 Polymorphisms in Breast Cancer Patients and Control Individuals

\begin{tabular}{|c|c|c|c|c|c|c|}
\hline $\begin{array}{l}\text { Polymorphism } \\
\text { (RefSNP) }\end{array}$ & Genotype & Allele & $\begin{array}{l}\text { Patients } \\
\mathrm{n}(\%)\end{array}$ & $\begin{array}{c}\text { Controls } \\
\mathrm{n}(\%)\end{array}$ & OR $(95 \%$ CI $)$ & p-value \\
\hline p.P47S & PP & & 199 (99.5) & $200(100.0)$ & - & - \\
\hline \multirow[t]{4}{*}{ (rs 1800371) } & PS & & $1(0.5)$ & $0(0.00)$ & - & - \\
\hline & SS & & & & & \\
\hline & & $\mathrm{P}$ & 399 (99.75) & $400(100.0)$ & - & - \\
\hline & & S & $1(0.25)$ & $0(0.00)$ & - & - \\
\hline p.R72P & $\mathrm{RR}$ & & $47(23.5)$ & $67(33.5)$ & Reference & \\
\hline \multirow[t]{5}{*}{ (rs1042522) } & $\mathrm{RP}$ & & $103(51.5)$ & $91(45.5)$ & $1.61(1.01-2.58)$ & 0.04 \\
\hline & PP & & $50(25.0)$ & $42(21.0)$ & $1.70(0.97-2.95)$ & 0.84 \\
\hline & $\mathrm{RP}+\mathrm{PP}$ & & $153(76.5)$ & $133(66.5)$ & $1.64(1.06-2.54)$ & 0.02 \\
\hline & & $\mathrm{R}$ & $197(49.3)$ & $225(56.3)$ & Reference & \\
\hline & & $\mathrm{P}$ & $203(50.7)$ & 175 (43.7) & $1.32(1.00-1.75)$ & 0.04 \\
\hline PIN3 Ins16bp & A1A1 & & $134(67.0)$ & $137(68.5)$ & Reference & \\
\hline \multirow[t]{5}{*}{ (rs17878362) } & $\mathrm{A} 1 \mathrm{~A} 2$ & & $52(26.0)$ & $55(27.5)$ & $0.97(0.62-1.51)$ & 0.88 \\
\hline & $\mathrm{A} 2 \mathrm{~A} 2$ & & $14(07.0)$ & $8(04.0)$ & $1.79(0.73-4.40)$ & 0.19 \\
\hline & $\mathrm{A} 1 \mathrm{~A} 2+\mathrm{A} 2 \mathrm{~A} 2$ & & $66(33.0)$ & $63(31.5)$ & $1.07(0.70-1.63)$ & 0.74 \\
\hline & & A1 & $320(80.0)$ & $329(82.3)$ & Reference & \\
\hline & & $\mathrm{A} 2$ & $80(20.0)$ & $71(17.7)$ & $1.15(0.81-1.65)$ & 0.41 \\
\hline p.R213R & $\mathrm{AA}$ & & $200(100.0)$ & $200(100.0)$ & - & - \\
\hline \multirow[t]{4}{*}{ (rs1800372) } & $\mathrm{AG}$ & & $0(0.00)$ & $0(0.00)$ & - & - \\
\hline & GG & & $0(0.00)$ & $(0.00)$ & - & - \\
\hline & & A & $400(100.0)$ & $400(100.0)$ & - & - \\
\hline & & $\mathrm{G}$ & $(0.00)$ & $(0.00)$ & - & - \\
\hline r.13494g $>\mathrm{a}$ & GG & & $124(62.0)$ & 135 (67.5) & Reference & \\
\hline \multirow[t]{5}{*}{ (rs1625895) } & GA & & $66(33.0)$ & $56(28.0)$ & $1.28(0.83-1.98)$ & 0.25 \\
\hline & AA & & $10(05.0)$ & $9(4.5)$ & $1.21(0.48-3.08)$ & 0.90 \\
\hline & $\mathrm{GA}+\mathrm{AA}$ & & $76(38.0)$ & $65(32.5)$ & $1.27(0.84-1.92)$ & 0.24 \\
\hline & & G & $314(78.5)$ & $326(81.5)$ & Reference & \\
\hline & & A & $86(21.5)$ & $74(18.5)$ & $1.20(0.85-1.70)$ & 0.28 \\
\hline
\end{tabular}

*n- Number of subjects, Figures in parentheses represents frequency of each genotype and allele; OR- Odds ratio; CI- confidence interval. Statistically significant p-values $(\mathrm{p}<0.05)$ are indicated in bold 


\section{Statistical Analysis}

The statistical analysis was done to evaluate association of screened polymorphisms with breast cancer risk. Hardy Weinberg Equilibrium (HWE) was tested by comparing the observed to expected genotype frequencies in controls using the Chi-square $(\chi 2)$ test. This test was used to demonstrate the significant difference of genotype and allele frequencies between the breast cancer patients and normal controls. The odds ratios (OR) with $95 \%$ confidence interval (CI) were estimated to calculate the relative risk of breast cancer susceptibility for each genotype and allele. A value of $\mathrm{p}<0.05$ was considered statistically significant. All the statistical values were calculated using SPSS (Version 16, SPSS Inc, Chicago, IL).

\section{Results}

\section{General characteristics of study subjects}

This case-control study consisted of 200 sporadic breast cancer patients (197 females and 3 males) and 200 gender and age matched unrelated healthy control individuals (197 females and 3 males). The mean age was $49.4 \pm 11.9$ years (Range $25-85$ years) for the cases and 47.1 \pm 12.5 years (Range $24-80$ years) for the controls. Breast cancer incidence was higher among individuals more than 40 years of age ( $80 \%$ ) compared to those less than 40 years $(20 \%)$. Out of 200 patients, 22 had stage I, 110 had stage II, 53 had stage III and 15 had stage IV tumors.

\section{Association between TP53 polymorphisms and breast} cancer risk

The genotyping results of the five polymorphisms of TP53 (p.P47S, p.R72P, PIN3 Ins16bp, p.R213R and r.13494g>a) are presented in Table 2. The observed genotypes frequencies of two polymorphisms (p.R72P and r.13494g $>a$ ) were in HWE ( $p>0.05)$. In PIN3 Ins16bp polymorphism, we observed deviation from HWE in patients $(\mathrm{p}<0.05)$ which could be attributed to selection bias. For p.P47S polymorphism, we observed the PP genotype in $99.5 \%$ of the patients and PS genotype in only 1 patient. All the controls had the wild type PP genotype.

The frequencies of RR, RP and PP genotype of p.R72P was found to be $23.5 \%$ vs $33.5 \%, 51.5 \%$ vs $45.5 \%$ and $25 \%$ vs $21 \%$ in patients and controls respectively. Heterozygous (RP) genotype was increased in breast cancer patients as compared to controls ( 51.5 vs $45.5 \%$ ) and showed 1.61 folds significantly increased risk for breast cancer $(\mathrm{OR}=1.61,95 \% \mathrm{CI}, 1.01-2.58, \mathrm{p}=0.04)$. Carrier of $\mathrm{P}$ allele (RP+PP) also demonstrated 1.64 folds increased risk for breast cancer $(\mathrm{OR}=1.64,95 \% \mathrm{CI}, 1.06$ 2.54; $\mathrm{p}=0.02)$. The frequencies of $\mathrm{R}$ and $\mathrm{P}$ allele were 49.3 vs $56.3 \%$ and 50.7 vs $43.7 \%$ in patients and controls respectively.

In breast cancer patients the frequencies of A1A1,A1A2 and $\mathrm{A} 2 \mathrm{~A} 2$ genotypes of PIN3 Ins16bp polymorphism was $67 \%, 26 \%$ and $7 \%$ respectively whereas in controls the genotype frequencies were $68.5 \%, 27.5 \%$ and $4 \%$ respectively. No significant difference was observed in the genotype and allele frequency between the breast cancer patients and controls. Carriers of A2 allele (A1A2+A2A2) were higher in patients as compared to the controls but the results were not statistically significant ( $\mathrm{p}=0.74)$.

For p.R213R (c.639A $>$ G), none of the breast cancer patients and controls analyzed exhibited A to $\mathrm{G}$ nucleotide substitution at position 639, and all individuals had homozygous wild type genotype. The frequencies of GG, GA and AA genotypes of TP53 r.13494g $>$ a polymorphism were 62 vs $67.5 \%, 33$ vs $28 \%$ and 5 vs $4.5 \%$ in patients and controls respectively. There was no significant difference between genotype and allele frequency in the breast cancer patients and controls.

To study the association between breast cancer and possible combinations of the TP53 polymorphisms, we performed genotype-genotype combination analysis

Table 3. Interaction between p.R72P, PIN3 Ins16bp and r.13494g>a Polymorphisms in Breast Cancer Patients and Healthy Controls

\begin{tabular}{|c|c|c|c|c|}
\hline Combination & $\begin{array}{c}\text { No. } \\
\text { of patients } \\
\mathrm{n}(\%)\end{array}$ & $\begin{array}{c}\text { No. } \\
\text { of controls } \\
\mathrm{n}(\%)\end{array}$ & $\begin{array}{c}\text { OR } \\
(95 \% \mathrm{CI})\end{array}$ & $\mathrm{p}$-value \\
\hline \multicolumn{5}{|c|}{ p.R72P-PIN3 Ins16bp } \\
\hline RR-A1A1 & $46(23.0)$ & $60(30.0)$ & Reference & \\
\hline RR-A1A2 & $1(0.5)$ & $7(3.5)$ & $0.19(0.02-1.57)$ & 0.14 \\
\hline RP-A1A1 & $71(35.5)$ & $56(28.0)$ & $1.65(0.98-2.78)$ & 0.05 \\
\hline RP-A1A2 & $30(15.0)$ & $33(16.5)$ & $1.18(0.63-2.22)$ & 0.60 \\
\hline $\mathrm{RP}-\mathrm{A} 2 \mathrm{~A} 2$ & $2(1.0)$ & $1(0.5)$ & $\mathrm{NC}$ & $\mathrm{NC}$ \\
\hline PP-A1A1 & $17(8.5)$ & $21(10.5)$ & $1.06(0.50-2.23)$ & 0.89 \\
\hline PP-A1A2 & $21(10.5)$ & $15(7.5)$ & $1.82(0.85-3.93)$ & 0.13 \\
\hline PP-A2A2 & $12(6.0)$ & $7(3.5)$ & $2.24(0.81-6.13)$ & 0.11 \\
\hline \multicolumn{5}{|c|}{ PIN3 Ins16bp-r.13494g>a } \\
\hline A1A1-GG & $118(59.0)$ & $124(62.0)$ & Reference & \\
\hline A1A2-GG & $6(3.0)$ & $11(5.5)$ & $0.57(0.20-0.60)$ & 0.28 \\
\hline A1A1-AG & $16(8.0)$ & $13(6.5)$ & $1.29(0.60-2.80)$ & 0.51 \\
\hline A1A2-AG & $41(20.5)$ & $41(20.5)$ & $1.05(0.64-1.73)$ & 0.84 \\
\hline A2A2-AG & $9(4.5)$ & $2(1.0)$ & $\mathrm{NC}$ & $\mathrm{NC}$ \\
\hline A1A2-AA & $5(2.5)$ & $3(1.5)$ & $\mathrm{NC}$ & $\mathrm{NC}$ \\
\hline A2A2-AA & $5(2.5)$ & $6(3.0)$ & $0.87(0.26-2.95)$ & 0.82 \\
\hline \multicolumn{5}{|c|}{ p.R72P-r.13494g >a } \\
\hline RR-GG & $44(22.0)$ & $62(31.0)$ & Reference & \\
\hline RR-AG & $1(0.5)$ & $4(2.0)$ & $\mathrm{NC}$ & $\mathrm{NC}$ \\
\hline RR-AA & $0(0.0)$ & $1(0.5)$ & $\mathrm{NC}$ & $\mathrm{NC}$ \\
\hline RP-GG & $66(33.0)$ & $54(27.0)$ & $1.72(1.01-2.92)$ & 0.04 \\
\hline RP-AG & $37(18.5)$ & $37(18.5)$ & $1.41(0.77-2.56)$ & 0.26 \\
\hline RP-AA & $2(1.0)$ & $0(0.0)$ & $\mathrm{NC}$ & $\mathrm{NC}$ \\
\hline PP-GG & $14(7.0)$ & $19(9.5)$ & $1.04(0.47-2.29)$ & 0.92 \\
\hline \multicolumn{5}{|c|}{ p.R72P- PIN3 Ins16bp - r.13494g>a } \\
\hline RR-A1A1-GG & $45(22.5)$ & $59(29.5)$ & Reference & \\
\hline RP-A1A2-AG & $24(12.0)$ & $26(13.0)$ & $1.21(0.61-2.38)$ & 0.58 \\
\hline RP-A1A1-GG & $60(30.0)$ & $47(23.5)$ & $1.67(0.97-2.88)$ & 0.06 \\
\hline PP-A1A2-AG & $17(8.5)$ & $12(6.0)$ & $1.85(0.80-4.27)$ & 0.14 \\
\hline PP-A1A1-GG & $13(6.5)$ & $18(9.0)$ & $0.95(0.42-2.13)$ & 0.89 \\
\hline PP-A1A2-AA & $3(1.5)$ & $2(1.0)$ & - & - \\
\hline RP-A1A2-AA & $2(1.0)$ & - & - & - \\
\hline PP-A2A2-AG & $7(3.5)$ & $1(0.5)$ & - & - \\
\hline PP-A1A1-AG & $4(2.0)$ & $2(1.0)$ & - & - \\
\hline RP-A1A1-AG & $11(5.5)$ & $10(5.0)$ & $1.44(0.56-3.69)$ & $0.44^{*}$ \\
\hline PP-A2A2-AA & $5(2.5)$ & $6(3.0)$ & - & - \\
\hline RR-A1A1-AG & $1(0.5)$ & $1(0.5)$ & - & - \\
\hline RP-A1A2-GG & $4(2.0)$ & - & - & - \\
\hline PP-A1A2-GG & $1(0.5)$ & $1(0.5)$ & - & - \\
\hline RP-A2A2-AG & $2(1.0)$ & $1(0.5)$ & - & - \\
\hline RP-A1A2-GG & $1(0.5)$ & $7(3.5)$ & - & - \\
\hline RR-A1A2-AG & - & $3(1.5)$ & - & - \\
\hline RR-A1A2-AA & - & $1(0.5)$ & - & - \\
\hline RR-A1A2-GG & - & $3(1.5)$ & - & - \\
\hline
\end{tabular}

$*_{n}$ - Number of subjects, Figures in parentheses represents frequency of each genotype and allele; OR- Odds ratio; CI- confidence interval. Statistically significant $\mathrm{p}$-values $(\mathrm{p}<0.05)$ are indicated in bold 
of three (p.R72P, PIN3 Ins16bp and r.13494g>a) polymorphisms (Table 3 ). We observed that interaction between p.R72P and PIN3 Ins16bp polymorphism (RPA1A1) showed significant risk of breast cancer (OR=1.65, 95\%CI: 0.98-2.78, $\mathrm{p}=0.05)$. The genotype combination RP-GG of p.R72P and r.13494g $>$ a polymorphism showed 1.72 folds risk for breast cancer $(\mathrm{OR}=1.72,95 \% \mathrm{CI}$ : 1.01 $2.92, \mathrm{p}=0.04)$. Analysis of genotype combinations of p.R72P, PIN3 Ins16bp and r.13494g>a polymorphisms of TP53 showed marginally significant risk for breast cancer in individuals with RP-A1A1-GG genotype combination $(\mathrm{OR}=1.67,95 \% \mathrm{CI}$ : $0.97-2.88, \mathrm{p}=0.06)$ (Table 3). The associations between the p.R72P, PIN3 Ins16bp, $\mathrm{r} .13494 \mathrm{~g}>\mathrm{a}$ polymorphisms and the risk of breast cancer were further examined with stratification on age at onset, menopausal status and clinical stage. No significant association was observed (data not shown).

\section{Discussion}

Breast cancer is a multifactorial disease resulting from the interaction between genetic and environmental factors (Pern et al., 2012). It has been demonstrated that P53 protein regulate activity of key effectors of cellular processes including DNA repair, cell cycle arrest, senescence and apoptosis (Levine, 1997; Riley et al., 2008). Functional inactivation of TP53 pathway is thought to affect TP53 signalling and further alter cancer risk (Moll and Schramm, 1998; Robles et al., 2002). TP53 is one of the major tumor suppressor genes which carry out essential functions in preservation of genome integrity (Costa et al., 2008). Over the last few years, several studies were conducted to investigate the association between individual TP53 polymorphism and breast cancer risk in different populations, however their results are ambiguous. In this hospital based study, we investigated the association between five potentially functional polymorphisms of TP53 (p.P47S, p.R72P,PIN3 Ins16bp, p.R213R and $r .13494 \mathrm{~g}>\mathrm{a}$ ) and risk of breast cancer in North Indian Punjabi population.

In the present study, only one patient out of 200 was heterozygous for $\mathrm{p} . \mathrm{P} 47 \mathrm{~S}$ polymorphism. This observation was in contrast to the previous report, showing a significant association between the mutant S47 phenotype and cancer risk (Felley-Bosco et al., 1993). S47 allele was also found to be associated with increased risk of developing colorectal cancer in South Indian population (Singamsetty et al., 2014). It has been reported that the S47 phenotype has a decreased capacity to induce apoptosis, to transactivate two (p53AIP1 and PUMA) p53 target genes, and to bind to MAPK1 protein as compared with the wild-type P47 phenotype (Li et al., 2005; Murphy, 2006). No association of p.P47S polymorphism was observed in Kuwaiti (Alawadi et al., 2011) and Saudi (Al-Qasem et al., 2012) breast cancer patients. Association of p.P47S polymorphism was also not observed in bladder (Santos et al., 2009), gliomas (Pinto et al., 2008), urinary bladder (Jaiswal et al., 2011), colorectal cancer (Sameer et al., 2010) and primary open angle glaucoma (Daugherty et al., 2009). The low frequency of p.P47S polymorphism in our population also indicates that $\mathrm{p} . \mathrm{P} 4 \mathrm{SS}$ polymorphism is not implicated in breast cancer.

In the present study, we observed significant association of RP genotype and Pro allele with increased breast cancer risk. Similarly, RP genotype has been reported to be associated with increased breast cancer risk in Iranian population (Boroujeni et al., 2013). Association of Pro allele with increased risk of breast cancer has been reported in Swedish (Sjalander et al., 1996), American (Weston et al., 1997), German (Wang-Gohrke et al., 1998, 2002), Russian (Suspitsin et al., 2003), Japanese (Huang et al., 2003; Noma et al., 2004), Slovakian (Franekova et al., 2007), Turkish (Akkiprik et al., 2009), Iranian (Kazemi et al., 2009), Kashmiri (Sayeed et al., 2010), Arabic (Alawadi et al., 2011), Austrian (Proestling et al., 2012) and Spanish (Rodrigues et al., 2013) population. Individuals with PP genotype had an increased risk of developing a cancer over their lifetimes compared to individuals with RR genotype (van Heemst et al., 2005).

No significant difference was observed in the frequency of RR genotype between the patients $(23.5 \%)$ and controls $(33.5 \%)$ in the present study. Similarly, no association between TP53 codon 72 variants and breast cancer risk was observed in Japanese (Kawajiri et al., 1993), Pakistani (Khaliq et al., 2000), Tunisian (Mabrouk et al., 2003), Finnish (Tommiska et al., 2005), Iranian (Khadang et al., 2007), Brazilian (Vieira et al., 2008) and South Indian populations (Suresh et al., 2011; Vijayaraman et al., 2012). Contrary to our results, association between RR genotype and breast cancer risk have been reported in Turkish (Buyru et al., 2003), Italian (Bonafe et al., 2003), Jewish (Ohayon et al., 2005), Greek (Papadakis et al., 2000; Kalemi et al., 2005), Brazilian (Damin et al., 2006; Aoki et al., 2009) and Chinese (Ma et al., 2006) population.

RR genotype has been described as a potential risk factor, while the RP as a protection factor against breast cancer among Saudi women (Al-Qasem et al., 2012). The R72 variant is more susceptible than P72 variant to degradation induced by human papillomavirus E6 protein, which may result in an increased susceptibility to human papillomavirus induced tumors in homozygous R72 individuals (Storey et al., 1998). Recently, a metaanalysis on twenty Indian case control studies with total of 3,258 cancer cases and 4,260 healthy controls did not find any significant association of p.R72P polymorphism with cancer risk (Mandal et al., 2014).

The R72 variant has been reported to be a more potent inhibitor of chemotherapy-induced apoptosis than the P72 variant (Bergamaschi et al., 2003). Patients, homozygous for R72 allele, with breast, lung or head and neck cancers have been shown to survive and respond better to chemotherapy and radiotherapy (Sullivan et al., 2004; Nelson et al., 2005; Tommiska et al., 2005; Xu et al., 2005).

It has been reported that intronic variants may affect gene regulation through aberrant splicing or through disruption of critical DNA-protein interactions (Hillebrandt et al., 1996). In the present study PIN3 Ins16bp polymorphism was not found to be associated with the risk of developing breast cancer. Similar to our results, no association of PIN3 Ins16bp polymorphism 
with risk of breast cancer was observed in Turkish (Akkiprik et al., 2009), Arabian (Alawadi et al., 2011) and Iranian (Pouladi et al., 2014) patients. In the present study higher frequency of A2A2 genotype was observed in the patients $(7 \%)$ as compared to the controls (4\%) but the results were not statistically significant. The A2A2 genotype has been reported to be associated with increased breast cancer risk in several studies (Weston et al., 1997; Wang-Gohrke et al., 2002, Costa et al., 2008; Guleria et al., 2012). On the contrary, six fold increased risk for breast cancer in individuals with A1A1 genotype has been reported in Slovakian population (Franekova et al., 2007). In the present study, carriers of A2 allele $(\mathrm{A} 1 \mathrm{~A} 2+\mathrm{A} 2 \mathrm{~A} 2)$ were higher in patients as compared to the controls but the results were not statistically significant $(\mathrm{p}=0.74)$. Association of A1A2 genotype with breast cancer risk has been reported in Iranian women (Faghani et al., 2011). A recent meta-analysis showed significant association of 16bp duplication polymorphism of TP53 with an increased risk of breast cancer (Wu et al., 2013). Though, no association of PIN3 Ins16bp polymorphism with increased breast cancer risk has been reported (De Vecchi et al., 2008; Hrstka et al., 2009; Trifa et al., 2010), the breast cancer patients with A2A2 genotype of PIN3 polymorphism were reported to have better survival when treated with anthracycline based chemotherapy (Bisof et al., 2012).

For p.R213R (c.639A>G), all subjects had homozygous wild type genotype. Thus, there was no association of p.R213R polymorphism with breast cancer similar to reports in ovarian (Mazars et al., 1992), Barretts esophagus patients (Pilger et al., 2007) and different tumors (Iihan et al., 1995).

In the present study, no association of $\mathrm{r} .13494 \mathrm{~g}>\mathrm{a}$ polymorphism was observed with the risk of developing breast cancer. Similar findings were documented in Caucasians (Mavridou et al., 1998), Turkish (Akkiprik et al., 2009) and Spanish (Rodrigues et al., 2013) breast cancer patients. In contrast to our results, association of r.13494g $>$ a polymorphism with the risk of developing breast (Peller et al., 1995), ovarian (Wang-Gohrke et al., 1999) and colon (Peller et al., 1995) cancer has been reported. Functional analysis using an in vitro cell survival assay demonstrated that lymphoblastoid cell lines derived from patients with the $\mathrm{r} .13494 \mathrm{~g}>\mathrm{a}$ variant exhibited a reduced level of apoptosis after chemotherapy and prolonged cell survival following DNA damage (Lehman et al., 2000).

We observed that PR-A1A1 genotype combination of p.R72P and PIN3 Ins 16bp and RP-GG combination of p.R72P and $\mathrm{r} .13494 \mathrm{~g}>$ a polymorphism showed significant risk of breast cancer $(\mathrm{OR}=1.65,95 \% \mathrm{CI}$ : $0.98-2.78, \mathrm{p}=0.05$; $\mathrm{OR}=1.72,95 \% \mathrm{CI}: 1.01-2.92, \mathrm{p}=0.04)$. The RP-A1A1-GG genotype combination of p.R72P and PIN3 Ins16bp and $\mathrm{r} .13494 \mathrm{~g}>$ a polymorphism showed marginally significant risk for breast cancer in the study population $(\mathrm{OR}=1.67$, 95\%CI: $0.97-2.88, \mathrm{p}=0.06)$. Significant association of PIN3 Ins16bp and r.13494g>a polymorphisms with lymph node metastases and tumor aggressiveness has been previously documented in breast cancer patients (Hrstka et al., 2009). The difference in TP53 polymorphisms and cancer susceptibility in different countries indicates that additional factors like environmental factors, lifestyle and other genetic modifiers may modulate cancer susceptibility associated with these polymorphisms.

We observed that $80 \%$ of breast cancer patients were of age $>40$ years. In Asia, $84 \%$ of breast cancers are diagnosed from the age of 40 onwards (Ferlay et al., 2012). The interaction of p.R72P and PIN3 Ins16bp polymorphisms had been observed even in smaller sample size reported earlier (Guleria et al., 2012). In the current study, the role of p.R72P in breast cancer susceptibility was confirmed along with the PIN3 Ins16bp and r.13494g >a as it conferred increased risk. Women subjects of current study were exposed to agricultural chemicals, generally overweight/obese and the major tumor suppressor gene TP53 showing almost wild type genotypes. Wild-type p53 plays a crucial role in maintaining genomic stability by allowing the repair of damaged DNA through induction of a transient G1 arrest or eliminating the damaged cells by triggering apoptosis (Nigro et al., 1989). In light of increasing incidence of breast cancer being reported from the region further studies exploring the interaction of TP53 polymorphisms with other genes involved in DNA repair pathways would be beneficial in deriving more accurate risk markers.

\section{Acknowledgements}

We are thankful to the patients and controls for taking part in this study. The present study was supported by the UGC grant F.No.40-293/2011 (SR) sanctioned to KG. We are thankful to Dr. Geeta Sharma, Principal, Sri Guru Ram Das Institute of Medical Sciences and Research, Vallah, Amritsar, Punjab for their help in providing access to patients and facilities for execution of research work.

\section{References}

Adeli, K, Ogbonna, G (1990). Rapid purification of human DNA from whole blood for potential application in clinical chemistry laboratories. Clin Chem, 36, 261-4.

Akkiprik M, Sonmez O, Gulluoglu BM, et al (2009). Analysis of p53 gene polymorphisms and protein over-expression in patients with breast cancer. Pathol Oncol Res, 15, 359-68.

Alawadi S, Ghabreau L, Alsaleh M, et al (2011). P53 gene polymorphisms and breast cancer risk in Arab women. Med Oncol, 28, 709-15.

Al-Qasem A, Toulimat M, Tulbah A, et al (2012). The p53 codon 72 polymorphism is associated with risk and early onset of breast cancer among Saudi women. Oncol Lett, 3, 875-8.

Aoki MN, Herrera AC, Amarante MK, et al (2009). CCR5 and p53 codon 72 gene polymorphisms: Implications in breast cancer development. Int J Mol Med, 23, 429-35.

Avigad S, Barel D, Blau O, et al (1997). A novel germ line p53 mutation in intron 6 in diverse childhood malignancies. Oncogene, 14, 1541-5.

Bergamaschi D, Gasco M, Hiller L, et al (2003). p53 polymorphism influences response in cancer chemotherapy via modulation of p73-dependent apoptosis. Cancer Cell, 3, 387-402.

Bišof V, Salihović MP, Narančić NS, et al (2012). The TP53 gene polymorphisms and survival of sporadic breast cancer patients. Med Oncol, 29, 472-8. 
Bonafé M, Ceccarelli C, Farabegoli F, et al (2003). Retention of the p53 codon 72 arginine allele is associated with a reduction of disease-free and overall survival in arginine/ proline heterozygous breast cancer patients. Clin Cancer Res, 9, 4860-4.

Boroujeni HR, Karimi M, Moshkelani S, et al (2013). Association of the p53 codon 72 polymorphism with breast cancer in central part of Iran. African J Pharmacy Pharmacology, 7, 356-9.

Buyru N, Tigli H, Dalay N (2003). P53 codon 72 polymorphism in breast cancer. Oncol Rep, 10, 711-4.

Carbone D, Chiba I, Mitsudomi T (1991). Polymorphism at codon 213 within the p53 gene. Oncogene, 6, 1691-2.

Chumakov PM, Jenkins JR. (1991). BstNI/NciI polymorphism of the human p53 gene (TP53). Nucleic Acids Res, 19, 6969.

Costa S, Pinto D, Morais A, et al (2005). Acetylation genotype and the genetic susceptibility to prostate cancer in a southern European population. Prostate, 64, 246-52.

Costa S, Pinto D, Pereira D, et al (2007). Importance of xeroderma pigmentosum group D polymorphisms in susceptibility to ovarian cancer. Cancer Lett, 246, 324-30.

Costa S, Pinto D, Pereira D, et al (2008). Importance of TP53 codon 72 and intron 3 duplication 16bp polymorphisms in prediction of susceptibility on breast cancer. BMC Cancer, $\mathbf{8}, 32$.

Damin AP, Frazzon AP, Damin DC, et al (2006). Evidence for an association of TP53 codon 72 polymorphism with breast cancer risk. Cancer Detect Prev, 30, 523-9.

Daugherty CL, Curtis H, Realini T, Charlton JF, Zareparsi S (2009). Primary open angle glaucoma in a Caucasian population is associated with the $\mathrm{p} 53$ codon 72 polymorphism. Mol Vis, 15, 1939-44.

De Vecchi G, Verderio P, Pizzamiglio S, et al (2008). The p53 Arg72Pro and Ins 16bp polymorphisms and their haplotypes are not associated with breast cancer risk in BRCA-mutation negative familial cases. Cancer Detect Prev, 32, 140-3.

DHFW (2013). State Wide Door to Door Campaign, Cancer Awareness and Symptom Based Early Detection. Government of Punjab, Chandigarh, India.

Dumont P, Leu JI, Della Pietra AC 3rd, George DL, Murphy M (2003). The codon 72 polymorphic variants of $\mathrm{p} 53$ have markedly different apoptotic potential. Nature Genet, $\mathbf{3 3}$, 357-65.

Faghani M, Ghasemi FM, Nikhbakht M, Salehi M (2011). TP53 PIN3 polymorphism associated with breast cancer risk in Iranian women. Indian J Cancer, 48, 298-302.

Felley-Bosco E, Weston A, Cawley HM, Bennett WP, Harris CC (1993). Functional studies of a germ-line polymorphism at codon 47 within the p53 gene. Am J Hum Genet, 53, 752-9.

Ferlay J, Soerjomataram I, Ervik M, et al (2012). GLOBOCAN 2012 v1 .0, Cancer Incidence and Mortality Worldwide: IARC Cancer Base No. 11 [Internet]. Lyon, France: International Agency for Research on Cancer; 2013. Available from: http:// globocan.iarc.fr, accessed on 31/05/2014

Franeková M,Zúbor P, Stanclová A, et al (2007). Association of p53 polymorphisms with breast cancer: a case-control study in Slovak population. Neoplasma, 54, 155-61.

Gemignani F, Moreno V, Landi S, et al (2004). A TP53 polymorphism is associated with increased risk of colorectal cancer and with reduced levels of TP53 mRNA. Oncogene, 23, 1954-6.

Guleria K, Sharma S, Manjari M, et al (2012). p.R72P, PIN3 Ins16bp polymorphisms of TP5 3 and CCR $5 \Delta 32$ in north Indian breast cancer patients. Asian Pac J Cancer Prev, 13, 3305-11.

Hillebrandt S, Streffer C, Demidchik EP, Biko J, Reiners C (1997). Polymorphisms in the p53 gene in thyroid tumours and blood samples of children from areas in Belarus. Mutat Res, 381, 201-7.

Hillebrandt S, Streffer C, Reiners C, Demidchik E (1996). Mutations in the p53 tumour suppressor gene in thyroid tumours of children from areas contaminated by the Chernobyl accident. Int J Radiat Biol, 69, 39-45.

Hrstka R, Beranek M, Klocova K, Nenutil R, Vojtesek B (2009). Intronic polymorphisms in TP53 indicate lymph node metastasis in breast cancer. Oncol Rep, 22, 1205-11.

Huang XE, Hamajima N, Katsuda N, et al, (2003). Association of p53 codon Arg72Pro and p73 G4C14-to A4T14 at exon 2 genetic polymorphisms with the risk of Japanese breast cancer. Breast Cancer, 10, 307-11.

Ilhan I, Erekul S, Ateşalp S, Ilhan O, Akar N (1995). p53 codon 213 (A-G) polymorphism in a Turkish population. Pediatr Hematol Oncol, 12, 499-501.

Isobe M, Emanuel BS, Givol D, Oren M, Croce CM (1986). Localization of gene for human $\mathrm{p} 53$ tumour antigen to band 17p13. Nature, 320, 84-5.

Jaiswal PK, Goel A, Mittal RD (2011). Association of p53 codon 248 (exon7) with urinary bladder cancer risk in the North Indian population. Biosci Trends, 5, 205-10.

Kalemi TG, Lambropoulos AF, Gueorguiev M, et al (2005). The association of $\mathrm{p} 53$ mutations and $\mathrm{p} 53$ codon 72 , Her 2 codon 655 and MTHFR C677T polymorphisms with breast cancer in Northern Greece. Cancer Lett, 222, 57-65.

Kawajiri K, Nakachi K, Imai K, Watanabe J, Hayashi S (1993). Germ line polymorphisms of p53 and CYP1A1 genes involved in human lung cancer. Carcinogenesis, 14, 1085-9.

Kazemi M, Salehi Z, Chakosari RJ (2009). TP53 codon 72 polymorphism and breast cancer in northern Iran. Oncol Res, 18, 25-30.

Khadang B, Fattahi MJ, Talei A, Dehaghani AS, Ghaderi A (2007). Polymorphism of TP53 codon 72 showed no association with breast cancer in Iranian women. Cancer Genet Cytogenet, 173, 38-42.

Khaliq S, Hameed A, Khaliq T, et al (2000). P53 mutations, polymorphisms, and haplotypes in Pakistani ethnic groups and breast cancer patients. Genet Test, 4, 23-9.

Lamb P, Crawford L (1986). Characterization of the human p53 gene. Mol Cell Biol, 6, 1379-85.

Lazar V, Hazard F, Bertin F, et al (1993). Simple sequence repeat polymorphism within the p53 gene. Oncogene, 8, 1703-5.

Lehman TA, Haffty BG, Carbone CJ, et al (2000). Elevated frequency and functional activity of a specific germ-line p53 intron mutation in familial breast cancer. Cancer Res, 60, 1062-9.

Levine AJ (1997). p53, the cellular gatekeeper for growth and division. Cell, 88, 323-31.

Levine AJ, Oren M. (2009). The first 30 years of p53: growing ever more complex. Nat Rev Cancer, 9, 749-58.

Li X, Dumont P, Della Pietra A, Shetler C, Murphy ME (2005). The codon 47 polymorphism in p53 is functionally significant. J Biol Chem, 280, 24245-51.

Ma H, Hu Z, Zhai X, et al (2006). Joint effects of single nucleotide polymorphisms in P53BP1 and p53 on breast cancer risk in a Chinese population. Carcinogenesis, 27, 766-71.

Mabrouk I, Baccouche S, El-Abed R, et al (2003). No evidence of correlation between $\mathrm{p} 53$ codon 72 polymorphism and risk of bladder or breast carcinoma inTunisian patients. Ann N Y Acad Sci, 1010, 764-70.

Malkinson AM, You M (1994).The intronic structure of cancer-related genes regulates susceptibility to cancer. $\mathrm{Mol}$ Carcinog, 10, 61-5.

Mandal RK, Yadav SS, Panda AK (2014). No evidence of correlation between $\mathrm{p} 53$ codon $72 \mathrm{G}>\mathrm{C}$ gene polymorphism 
and cancer risk in Indian population: a meta-analysis. Tumour Biol, (in press).

Mavridou D, Gornall R, Campbell IG, Eccles DM (1998). TP53 intron 6 polymorphism and the risk of ovarian and breast cancer. Br J Cancer, 77, 676-7.

Mazars GR, Jeanteur P, Lynch HT, Lenoir G, Theillet C (1992). Nucleotide sequence polymorphism in a hotspot mutation region of the p53 gene. Oncogene, 7, 781-2.

McDaniel T, Carbone D, Takahashi T, et al (1991). The MspI polymorphism in intron 6 of p53 (TP53) detected by digestion of PCR products. Nucleic Acids Res, 19, 4796.

Medeiros R, Vasconcelos A, Costa S, et al (2004). Metabolic susceptibility genes and prostate cancer risk in a southern European population: the role of glutathione S-transferases GSTM1, GSTM3, and GSTT1 genetic polymorphisms. Prostate, 58, 414-20.

Moll UM, Schramm LM (1998). p53 an acrobat in tumorigenesis. Crit Rev Oral Biol Med, 9, 23-37.

Murphy ME (2006). Polymorphic variants in the p53 pathway. Cell Death Differ, 13, 916-20.

Nigro JM, Baker SJ, Preisinger AC, et al (1989). Mutations in p53gene occur in diverse human tumor types. Nature, 342, 705-8.

Noma C, Miyoshi Y, Taguchi T, Tamaki Y, Noguchi S (2004). Association of p53 genetic polymorphism (Arg72Pro) with estrogen receptor positive breast cancer risk in Japanese women. Cancer Lett, 210, 197-203.

Ohayon T, Gershoni-Baruch R, Papa MZ, et al (2005). The R72P P53 mutation is associated with familial breast cancer in Jewish women. Br J Cancer, 92, 1144-8.

Orsted DD, Bojesen SE, Tybjaerg-Hansen A, Nordestgaard BG (2007). Tumor suppressor p53 Arg72Pro polymorphism and longevity, cancer survival, and risk of cancer in the general population. J Exp Med, 204, 1295-1301.

Papadakis EN, Dokianakis DN, Spandidos DA (2000). p53 codon 72 polymorphism as a risk factor in the development of breast cancer. Mol Cell Biol Res Commun, 3, 389-92.

Peller S, Kopilova Y, Slutzki S, et al (1995). A novel polymorphism in intron 6 of the human p53 gene: a possible association with cancer predisposition and susceptibility. DNA Cell Biol, 14, 983-90.

Perfumo C, Bonelli L, Menichini P, et al (2006). Increased risk of colorectal adenomas in Italian subjects carrying the $\mathrm{p} 53$ PIN3 A2-Pro72 haplotype. Digestion, 74, 228-35.

Pern F, Bogdanova N, Schürmann P, et al (2012). Mutation analysis of BRCA1, BRCA2, PALB2 and BRD7 in a hospital-based series of German patients with triple-negative breast cancer. PLoS One, 7, e47993.

Pilger DA, Lopez PL, Segal F, Leistner-Segal S (2007). Analysis of R213R and $13494 \mathrm{~g}>\mathrm{a}$ polymorphisms of the p53 gene in individuals with esophagitis, intestinal metaplasia of the cardia and Barrett's esophagus compared with a control group. Genomic Med, 1, 57-63.

Pim D, Banks L (2004). p53 polymorphic variants at codon 72 exert different effects on cell cycle progression. Int $J$ Cancer, 108, 196-9.

Pinto D, Vasconcelos A, Costa S, et al (2004). HER2 polymorphism and breast cancer risk in Portugal. Eur $J$ Cancer Prev, 13, 177-81.

Pinto GR, Yoshioka FK, Silva RL, et al (2008). Prognostic value of TP53 Pro47Ser and Arg72Pro single nucleotide polymorphisms and the susceptibility to gliomas in individuals from Southeast Brazil. Genet Mol Res, 7, 207-16.

Pouladi N, Kouhsari SM, Feizi MH, et al (2014). Lack of association of intron $316 \mathrm{bp}$ polymorphism of TP53 with breast cancer among Iranian-Azeri patients. Asian Pac J Cancer Prev, 15, 2631-4.
Proestling K, Hebar A, Pruckner N, et al (2012). The Pro allele of the 53 codon 72 polymorphism is associated with decreased intratumoral expression of BAX and p21, and increased breast cancer risk. PLoS One, 7, e47325.

Riley T, Sontag E, Chen P, Levine A (2008).Transcriptional control of human p53-regulated genes. Nat Rev Mol Cell Biol, 9, 402-12.

Robles AI, Linke SP, Harris CC (2002). The p53 network in lung carcinogenesis. Oncogene, 21, 6898-907.

Rodrigues P, Furriol J, Tormo E, et al (2013). Epistatic interaction of Arg72Pro TP53 and -710 C/T VEGFR1 polymorphisms in breast cancer: predisposition and survival. Mol Cell Biochem, 379, 181-90.

Sagne C, Marcel V, Amadou A, et al (2013). A meta-analysis of cancer risk associated with the TP53 intron 3 duplication polymorphism (rs17878362): geographic and tumor-specific effects. Cell Death Dis, 4, e492.

Sameer AS, Shah ZA, Syeed N, et al (2010). TP53 Pro47Ser and Arg72Pro polymorphisms and colorectal cancer predisposition in an ethnic Kashmiri population. Genet Mol Res, 9, 651-60.

Santos LE, Guilhen AC, de Andrade RA, Sumi LG, Ward LS (2011). The role of TP53 Pro47Ser and Arg72Pro single nucleotide polymorphisms in the susceptibility to bladder cancer. Urol Oncol, 29, 291-4.

Sayeed N, Sameer AS, Abdullah S, et al (2010). A case-control study of TP53 R72P polymorphism in breast cancer patients of ethnic Kashmiri population. World J Oncol, 1, 236-41.

Singamsetty GK, Malempati S, Bhogadhi S, et al (2014). TP53 alterations and colorectal cancer predisposition in south Indian population: a case-control study. Tumour Biol, 35, 2303-11.

Själander A, Birgander R, Hallmans G, et al (1996). p53 polymorphisms and haplotypes in breast cancer. Carcinogenesis, 17, 1313-6.

Soussi T, Lozano G (2005). p53 mutation heterogeneity in cancer. Biochem Biophys Res Commun, 331, 834-42.

Storey A, Thomas M, Kalita A, et al (1998). Role of a p53 polymorphism in the development of human papillomavirusassociated cancer. Nature, 393, 229-34.

Sullivan A, Syed N, Gasco M, et al (2004). Polymorphism in wild-type p53 modulates response to chemotherapy in vitro and in vivo. Oncogene, 23, 3328-37.

Surekha D, Sailaja K, Rao DN, et al (2011). Codon 72 and G13964C intron 6 polymorphisms of TP53 in relation to development and progression of breast cancer in India. Asian Pac J Cancer Prev, 12, 1893-8.

Suresh K, Venkatesan R, Chandirasekar R, Kumar BL, Sasikala (2011). Association of Trp53 arg72pro polymorphic variants with breast cancer - a case control study in south Indian population. Biology Medicine, 3, 15-22.

Suspitsin EN, Buslov KG, Grigoriev MY, et al (2003). Evidence against involvement of $\mathrm{p} 53$ polymorphism in breast cancer predisposition. Int $J$ Cancer, 103, 431-3.

The Tribune, Chandigarh, India. 18 die of cancer in Punjab everyday. 2013. http://www.tribuneindia. com/2013/20130129/main3.htm [January 29; 2013]

Thomas M, Kalita A, Labrecque S, et al (1999). Two polymorphic variants of wild-type p53 differ biochemically and biologically. Mol Cell Biol, 19, 1092-100.

Tommiska J, Eerola H, Heinonen M, et al (2005). Breast cancer patients with 553 Pro72 homozygous genotype have a poorer survival. Clin Cancer Res, 11, 5098-103

Trifa F, Karray-Chouayekh S, Mabrouk I, et al (2010). Haplotype analysis of p53 polymorphisms: Arg72Pro, Ins16bp and G13964C in Tunisian patients with familial or sporadic breast cancer. Cancer Epidemiol, 34, 184-8. 
Van Heemst D, Mooijaart SP, Beekman M, et al, (2005). Variation in the human TP53 gene affects old age survival and cancer mortality. Exp Gerontol, 40, 11-5.

Vieira JO, da Silva ID, Higo PE, Nogueira-de-Souza NC, Gebrim LH (2008). Study of p53 codon 72 polymorphism in patients with breast cancer. Eur J Gynaecol Oncol, 29, 364-7.

Vijayaraman KP, Veluchamy M, Murugesan P, Shanmugiah KP,Kasi PD (2012). p53 exon 4 (codon 72) polymorphism and exon 7 (codon 249) mutation in breast cancer patients in southern region (Madurai) of Tamil Nadu. Asian Pac J Cancer Prev, 13, 511-6.

Wajapeyee N, Somasundaram K (2004). Pharmacogenomics in breast cancer: current trends and future directions. Curr Opin Mol Ther, 6, 296-301.

Walerych D, Napoli M, Collavin L, Del Sal G (2012). The rebel angel: mutant p53 as the driving oncogene in breast cancer. Carcinogenesis, 33, 2007-17.

Wang-Gohrke S, Becher H, Kreienberg R, Runnebaum IB, Chang-Claude J (2002). Intron 316 bp duplication polymorphism of p53 is associated with an increased risk for breast cancer by the age of 50 years. Pharmacogenetics, 12, 269-72.

Wang-Gohrke S, Rebbeck TR, Besenfelder W, et al (1998). p53 germline polymorphisms are associated with an increased risk for breast cancer in German women. Anticancer Res, 18, 2095-9.

Wang-Gohrke S, Weikel W, Risch H, et al (1999). Intron variants of the $\mathrm{p} 53$ gene are associated with increased risk for ovarian cancer but not in carriers of BRCA1 or BRCA2 germline mutations. Br J Cancer, 81, 179-83.

Weston A, Pan CF, Ksieski HB, et al (1997).p53 haplotype determination in breast cancer. Cancer Epidemiol Biomarkers Prev, 6, 105-12.

Whibley C, Pharoah PD, Hollstein M (2009). p53 polymorphisms: cancer implications. Nat Rev Cancer, 9, 95-107.

Wu D, Zhang Z, Chu H, et al (2013). Intron 3 sixteen base pairs duplication polymorphism of p53 contributes to breast cancer susceptibility: evidence from meta-analysis. PLoS One, 8, e61662.

Wu X, Zhao H, Amos CI, et al (2002). p53 genotypes and haplotypes associated with lung cancer susceptibility and ethnicity. J Natl Cancer Inst, 94, 681-90.

Xu Y, Yao L, Ouyang T, et al (2005). p53 Codon 72 polymorphism predicts the pathologic response to neoadjuvant chemotherapy in patients with breast cancer. Clin Cancer Res, 11, 7328-33.

Zhang Z, Wang M, Wu D, et al (2010). P53 codon 72 polymorphism contributes to breast cancer risk: a metaanalysis based on 39 case-control studies. Breast Cancer Res Treat, 120, 509-17.

Zhou Y, Li N, Zhuang W, et al (2007). P53 codon 72 polymorphism and gastric cancer: a meta-analysis of the literature. Int J Cancer, 121, 1481-6. 